\section{Mental health of children and adolescents with intellectual disabilities in Britain}

\author{
ERIC EMERSON and CHRIS HATTON
}

Several well-constructed community-based population studies suggest that $35-40 \%$ of children and adolescents with intellectual disabilities ${ }^{1}$ are likely to have a diagnosable psychiatric disorder (Rutter et al, 1976; Einfeld \& Tonge, 1996; Linna et al, 1999; Stromme \& Diseth, 2000; Dekker et al, 2002; Dekker \& Koot, 2003; Emerson, 2003). However, few studies have either employed formal diagnostic criteria to examine prevalence rates of specific psychiatric disorders in contemporaneous samples of children with and without intellectual disability, or have investigated the direction and strength of association between personal/social/environmental factors and risk of psychiatric disorders for children with and without intellectual disabilities.

The aims of this study were: (a) to establish the prevalence of diagnosable psychiatric disorders against ICD-10 criteria (World Health Organization, 1993) among British children with and without intellectual disabilities; (b) to assess the association between exposure to psychosocial disadvantage and presence of psychiatric disorders in children with and without intellectual disabilities; (c) to estimate the extent to which elevated risk for psychiatric disorders among children with intellectual disabilities may be accounted for by elevated rates of exposure to psychosocial disadvantage.

\section{METHOD}

\section{Sample}

The present study involved secondary analysis of data collected in the 1999 and 2004 Office for National Statistics (ONS) surveys of the mental health of British children and adolescents (Meltzer et al, 2000; Green et al, 2005). Data files were obtained

I. The term 'intellectual disability' will be used synonymously with the terms 'learning disability' (as used in the UK) and 'mental retardation' (as used in the USA and ICD-I0). from the UK Data Archive (http://www. data-archive.ac.uk). The 1999 survey collected information on 10438 children between 5 and 15 years of age, which represented $83 \%$ of the target sample (Meltzer $e t$ al, 2000). The 2004 survey collected information on 7977 children between 5 and 16 years of age, which represented $76 \%$ of the target sample (Green et al, 2005). Both samples were stratified by age and gender within postcode sectors in England, Scotland and Wales. Comparison of the results from the 1999 and 2004 surveys has failed to reveal any meaningful changes in the prevalence of psychiatric disorders among the total sample of young people between these two time points (Green et al, 2005). In addition, our preliminary analyses indicated no significant variation across samples with regard to the hypotheses being examined. As a result, analyses were undertaken on the combined sample of 18415 children.

\section{Procedure}

The surveys used identical procedures for the collection of information, the identification of psychiatric disorders and the collection of information on child and family demographics and functioning. Information was collected by computer-assisted face-to-face personal interview with the child's primary carer (in $94 \%$ of cases the child's mother) and, wherever possible, with children aged 11 years or over. If consent was obtained from the child's primary carer, information was also collected by postal questionnaire from the child's teacher. Teacher information was available for $72 \%$ of the achieved sample. Children for whom teachers did not provide information were more likely to be supported by a lone parent $\left(27 v .22 \% ; \chi^{2}=64.0\right.$, d.f. $=1, P<0.001$; $O R=1.35$ ), more likely to be living in income poverty (36 v. $28 \% ; \quad \chi^{2}=87.0, \quad$ d.f. $=1, \quad P<0.001$; $\mathrm{OR}=1.41)$ and more likely to be living in families with poorer family functioning (20 v. $18 \%$; $\chi^{2}=16.9$, d.f. $=1, P<0.001$; $\mathrm{OR}=1.19$ ).

\section{Measures}

The presence of psychiatric disorders among the children and adolescents was identified through the use of the Development and Well-Being Assessment (DAWBA; Goodman et al, 2000). This consists of two structured interviews (one undertaken with the child's primary carer and the

Funding detailed in Acknowledgements. 
other, for children aged 11 years or more, with the child), a questionnaire used with the child's teacher and a computer-assisted diagnostic rating system that provides diagnoses against DSM-IV (American Psychiatric Association, 1994) and ICD-10 criteria. The time frame (period prevalence) for DAWBA questions is the previous month unless ICD-10 diagnostic criteria specify a minimum period for the duration for symptoms (e.g. 6 months for generalised anxiety disorder). The DAWBA has been shown to discriminate well between samples of children drawn from populationbased child benefit registers and from those attending child and adolescent mental health services, have good convergent validity with the Strengths and Difficulties Questionnaire (Goodman, 1999), predict contact with health services and prognosis, and possess acceptable levels of agreement with diagnoses derived from case-note review (Goodman et al, 2000). It has not, however, been validated on children with intellectual disabilities.

In addition, information was also collected in both 1999 and 2004 on indicators of family socio-economic position (occupation, income, education), life events, parental mental health using the 12-item General Health Questionnaire (GHQ-12; Goldberg $\&$ Williams, 1988), family functioning using the General Functioning Scale of the MacMaster Family Activity Device (Miller et al, 1985) and teacher ratings of child academic attainment. Income data were equivalised using the modified Organisation for Economic Cooperation and Development (OECD) scale (Department of Work and Pensions, 2007). Income poverty was defined as living in a household whose equivalised income was less that $60 \%$ of the national median for the sampled year.

\section{Identifying children with intellectual disabilities}

Following preliminary analysis we identified children and adolescents as having intellectual disabilities if one of the following conditions was met.

(a) The child's primary carer reported that the child had 'learning difficulties' and the child's teacher reported that either they had marked difficulty in all three areas of scholastic attainment assessed (reading, maths, spelling) or their estimated developmental quotient (DQ) fell two or more standard deviations below the sample average. Child DQ was calculated by dividing the child's mental age (as estimated by their teacher) by chronological age.

(b) The child's primary carer did not report that the child had 'learning difficulties' but the child's teacher reported that they had marked difficulty in all three areas of scholastic attainment assessed and their DQ fell two or more standard deviations below the average DQ.

(c) No information was available from the child's teacher but the child's primary carer reported that the child had 'learning difficulties' and that they had been concerned about the child's speech development in the first 3 years of life.

This approach identified 641 children (3.5\% of the total sample) as having intellectual disabilities and 17774 children as not having intellectual disabilities. Of the children with intellectual disabilities, 395 $(62 \%)$ were identified by combined parental and teacher report, $71(11 \%)$ by teacher report and $175(27 \%)$ by parental report. Children with intellectual disabilities were significantly more likely to be male (66 v . $50 \%, \chi^{2}=61.9$, d.f. $=1, P<0.001 ; \quad O R=$ 1.93). There were no differences between the two groups with regard to age (mean age 10.1 years) or ethnicity (90\% White).

\section{RESULTS}

\section{Prevalence of psychiatric disorders}

The point prevalence of psychiatric disorders for children and adolescents with and without intellectual disabilities is shown in Table 1 for all disorders with a prevalence of approximately $1 \%$ or greater for either group. Prevalence rates were higher among children with intellectual disabilities for 27 of the 28 comparisons and statistically significantly elevated $(P<0.01)$ for 20 of the 28 comparisons. Children with intellectual disabilities accounted for $14 \%$ of all British children with a diagnosable psychiatric disorder.

\section{Associated social and environmental factors}

Associations between gender, age and eight social/environmental variables and risk of having the three most common categories of psychiatric disorder (conduct disorder, emotional disorder including anxiety disorder, and hyperkinesis) are presented in Table 2 for children with and without intellectual disabilities. For emotional disorders the direction of effect is identical across the two groups for all potential risk factors. In addition, there is close correspondence in the strength of effect for eight of the ten variables. For conduct disorders the direction of effect is identical across the two groups for all potential risk factors. There is close correspondence in the strength of effect for four of the ten variables. For hyperkinesis, the direction of effect is identical across the two groups for eight of the ten variables, with close correspondence in the strength of effect for one variable.

A cumulative social risk index was derived from the eight potential social/environmental risk factors by counting the number of potential risk factors to which each child was exposed. The association between the cumulative social risk index and prevalence of emotional disorders, conduct disorders and hyperkinesis is shown in Fig. 1. Rank order correlations between cumulative social risk and prevalence were 1.0 $(P<0.001)$ for emotional disorders and for conduct disorders for children with and without intellectual disability, 0.93 $(P=0.008)$ for hyperkinesis among children with intellectual disability and 0.97 $(P<0.001)$ for hyperkinesis among children without intellectual disability. Although visual inspection of the data suggested a stronger association between cumulative social risk and prevalence among children with intellectual disabilities, post hoc tests for interaction effects (using a logistic regression model) were not significant.

\section{Rates of exposure to potential social and environmental risk factors}

Given the evidence that risk of emotional disorders, conduct disorders and hyperkinesis was associated with potential social/ environmental risk factors for both groups of children, we explored between-group rates of exposure to these potential risk factors (Table 3). Exposure to all eight indicators of potential social/environmental risk was significantly higher among children with intellectual disabilities $(P<0.001)$.

\section{Estimating risk after controlling for between-group differences in social/environmental risk factors}

Finally we estimated the extent to which intellectual disability represented a risk factor for psychiatric disorder after controlling for the marked between-group differences in 
Table I Point prevalence of psychiatric disorders among children and adolescents with and without intellectual disabilities'

\begin{tabular}{|c|c|c|c|}
\hline & \multicolumn{2}{|c|}{ Point prevalence, $\%$} & \multirow[t]{2}{*}{ Odds ratio $(95 \% \mathrm{Cl})$} \\
\hline & $\begin{array}{c}\text { With } \\
\text { intellectual } \\
\text { disability }\end{array}$ & $\begin{array}{l}\text { Without } \\
\text { intellectual } \\
\text { disability }\end{array}$ & \\
\hline Any psychiatric disorder & 36.0 & 8.0 & $6.5(5.4-7.7)^{* * *}$ \\
\hline Any emotional disorder & 12.0 & 3.7 & $3.6(2.8-4.6)^{* * *}$ \\
\hline Any anxiety disorder & 11.4 & 3.2 & $3.9(3.0-5.0)^{* * *}$ \\
\hline Separation anxiety & 2.7 & 0.6 & $4.9(2.9-8.3)^{* * *}$ \\
\hline Specific phobia & 2.0 & 0.8 & $2.4(1.4-4.3)^{* *}$ \\
\hline Social phobia & 0.9 & 0.3 & $3.3(1.4-7.7)^{* *}$ \\
\hline Panic disorder & 0.2 & 0.2 & $1.0(0.1-7.3)$ \\
\hline Agoraphobia & 0.2 & 0.1 & $1.7(0.2-13.1)$ \\
\hline Post-traumatic stress disorder & 0.5 & 0.2 & $3.1(0.9-10.2)$ \\
\hline Obsessive-compulsive disorder & 0.2 & 0.2 & $0.7(0.1-5.1)$ \\
\hline Generalised anxiety disorder & 1.6 & 0.6 & $2.5(1.3-4.9)^{* *}$ \\
\hline Other anxiety disorder & 4.4 & 0.9 & $4.8(3.2-7.2)^{* * *}$ \\
\hline Any depressive disorder & 1.4 & 0.9 & I.7 (0.8-3.3) \\
\hline Depressive episode & 0.9 & 0.6 & I.5 (0.7-3.4) \\
\hline Other depressive episode & 0.5 & 0.2 & $2.1(0.7-7.0)$ \\
\hline Hyperkinesis (ADHD) & 8.3 & 0.9 & $8.4(6.1-11.5)^{* * *}$ \\
\hline Any conduct disorder & 20.5 & 4.3 & $5.7(4.6-7.0)^{* * *}$ \\
\hline Oppositional defiant disorder & II.I & 2.3 & $5.3(4.1-6.9)^{* * *}$ \\
\hline Unsocialised conduct disorder & 1.9 & 0.4 & $4.9(2.8-8.5)^{* * *}$ \\
\hline Socialised conduct disorder & 1.3 & 0.9 & $2.1(1.2-3.8)^{* *}$ \\
\hline Other conduct disorder & 5.2 & 0.5 & $10.5(7.0-15.7)^{* * *}$ \\
\hline Autistic-spectrum disorder & 8.0 & 0.3 & $33.4(22.3-50.2)^{* * *}$ \\
\hline Tic disorder & 0.8 & 0.2 & $5.2(2.0-13.5)^{* *}$ \\
\hline Eating disorder & 0.2 & 0.1 & $\mathrm{I} .3(0.2-9.4)$ \\
\hline Emotional disorder + conduct disorder & 4.4 & 0.8 & $5.8(3.8-8.8)^{* * *}$ \\
\hline Conduct disorder + ADHD & 5.8 & 0.6 & $9.4(6.5-13.8)^{* * *}$ \\
\hline Emotional disorder + ADHD & 1.3 & 0.1 & $9.8(4.4-21.9)^{* * *}$ \\
\hline Emotional disorder + conduct disorder + ADHD & 0.8 & 0.1 & $8.7(3.2-23.9)^{* * *}$ \\
\hline
\end{tabular}

$* P<0.05 ; * * P<0.01 ; * * * P<0.001$.

ADHD, attention-deficit hyperactivity disorder.

I. Those with missing data were excluded from analyses.

exposure to potential social/environmental risk factors. We used binary logistic regression to estimate the corrected odds ratio for associated psychiatric disorder after controlling for between-group differences in age, gender and the eight potential social/ environmental risk factors (Table 4). Variables were entered in two blocks (block 1 comprising the variables related to the child's intellectual disability, gender and age and block 2 the eight potential social/ environmental risk factors in a forward conditional stepwise model; $P$ variable entry $<0.05, P$ variable exit $>0.1$ ).

Comparing the corrected odds ratio for intellectual disability at blocks 1 and 2 indicates that controlling for betweengroup differences in exposure to potential social/environmental risk involves a $51 \%$ reduction in attributable risk for emotional disorder, a $38 \%$ reduction for conduct disorder and a $33 \%$ reduction for hyperkinesis.

\section{DISCUSSION}

\section{Principal findings}

The results of the study indicated that: (a) the prevalence of a wide range of psychiatric disorders was significantly higher among children with intellectual disabilities than among children without: children with intellectual disabilities accounted for $14 \%$ of all British children with a diagnosable psychiatric disorder; (b) increased prevalence rates were particularly marked for autistic-spectrum disorder, hyperkinesis and any conduct disorders (the latter accounting for approximately two-thirds of all diagnoses among children with intellectual disabilities); (c) cumulative risk of exposure to social disadvantage was associated with increased prevalence rates for any emotional disorder, any conduct disorder and hyperkinesis among children with and without intellectual disabilities; (d) children with intellectual disabilities were at significantly greater risk of exposure to all forms of social disadvantage examined; (e) controlling for these between-group differences in rates of exposure to social disadvantage significantly reduced the increased risk of psychiatric disorders among children with intellectual disabilities.

\section{Strengths and limitations}

The main strengths of the present study are that it investigated the prevalence of diagnosable psychiatric disorders against ICD-10 criteria in a large nationally representative sample of British children with and without intellectual disabilities. The main weaknesses of the study lie in: (a) the identification of children with intellectual disability; (b) the use of a measure of psychiatric disorder that has not been validated for use with children with intellectual disabilities; (c) the use of a cross-sectional design.

With regard to the identification of children with intellectual disability, we attempted (wherever possible) to combine parent and teacher report. The overall prevalence rate of intellectual disabilities within the sample $(3.5 \%)$ is within the bounds reported in population-based epidemiological studies that have included children with mild intellectual disabilities (Leonard \& Wen, 2002). However, the ascertained prevalence rates are slightly higher than the commonly assumed prevalence of intellectual disability $(2-3 \%)$. It is therefore possible that our operational definition might have led to the inclusion of a small proportion of children with 'borderline' intellectual disabilities. It is not possible to predict the impact of this on our results. Confidence in our operational definition is somewhat strengthened by the (expected) association between prevalence and gender and poverty (Leonard \& Wen, 2002). 
Table 2 Association between personal, social and environmental variables and risk of emotional disorder, conduct disorder and hyperkinesis among children with and without intellectual disabilities

\begin{tabular}{|c|c|c|c|c|}
\hline & \multicolumn{2}{|c|}{ With intellectual disability } & \multicolumn{2}{|c|}{ Without intellectual disability } \\
\hline & OR & $95 \% \mathrm{Cl}$ & OR & $95 \% \mathrm{Cl}$ \\
\hline \multicolumn{5}{|l|}{ Emotional disorder } \\
\hline Male gender & 0.7 & $0.4-1.1$ & 0.8 & $0.7-0.9 * *$ \\
\hline Age II-16 years & 1.8 & I.I-3.0* & 1.9 & $1.6-2.2 * * *$ \\
\hline Lone parent family & 2.4 & $1.5-3.9 * * *$ & 2.2 & $1.9-2.6 * * *$ \\
\hline Income poverty & 2.2 & $1.3-3.9 * *$ & 2.2 & $1.9-2.6^{* * *}$ \\
\hline Exposure to two or more negative life events & 3.2 & $1.9-5.2 * * *$ & 3.3 & $2.8-3.8^{* * *}$ \\
\hline Poor family functioning ${ }^{2}$ & 2.5 & $1.5-4.1^{* *}$ & 2.2 & $1.9-2.6 * * *$ \\
\hline Primary carer has no educational qualifications & 1.8 & I.I-3.0* & 2.0 & $1.7-2.4^{* * *}$ \\
\hline Household with no paid employment & 2.3 & I.4-3.7** & 2.5 & $2.1-3.0^{* * *}$ \\
\hline Mother with potential mental health disorder ${ }^{3}$ & 2.5 & $1.5-4.1^{* *}$ & 3.6 & $3.1-4.3^{* * *}$ \\
\hline Maternal self-rated physical health less than 'good' & 1.5 & $0.8-2.6$ & 5.3 & $4.4-6.5^{* * *}$ \\
\hline \multicolumn{5}{|l|}{ Conduct disorder } \\
\hline Male gender & 2.3 & $1.5-3.7^{* * *}$ & 2.1 & $1.8-2.4^{* * *}$ \\
\hline Age II-16 years & 1.2 & $0.8-1.8$ & 1.4 & $1.2-1.7^{* * *}$ \\
\hline Lone-parent family & 2.3 & $1.5-3.4 * * *$ & 2.4 & $2.1-2.8^{* * *}$ \\
\hline Income poverty & 1.7 & $1.1-2.5^{*}$ & 2.9 & $2.5-3.4^{* * *}$ \\
\hline Exposure to two or more negative life events & 2.1 & $1.4-3.1 * * *$ & 3.4 & $2.9-3.9 * * *$ \\
\hline Poor family functioning ${ }^{2}$ & 1.7 & I.I-2.5* & 3.8 & $3.2-4.4^{* * *}$ \\
\hline Primary carer has no educational qualifications & 2.2 & $1.5-3.3 * * *$ & 2.4 & $2.0-2.8^{* * *}$ \\
\hline Household with no paid employment & 2.0 & $1.3-2.9 * *$ & 3.2 & $2.7-3.7^{* * *}$ \\
\hline Mother with potential mental health disorder ${ }^{3}$ & 2.0 & $1.3-3.0 * *$ & 3.4 & $3.0-4.0 * * *$ \\
\hline Maternal self-rated physical health less than 'good' & 1.8 & I.I-2.8* & 3.0 & $2.4-3.7^{* * *}$ \\
\hline \multicolumn{5}{|l|}{ Hyperkinesis } \\
\hline Male gender & 3.2 & $1.5-6.9 * *$ & 6.5 & $4.3-9.8^{* * *}$ \\
\hline Age $5-10$ years & 2.0 & I.I-3.6* & 0.9 & $0.7-1.2$ \\
\hline Lone parent family & 1.3 & $0.7-2.4$ & 2.1 & $1.6-2.8^{* * *}$ \\
\hline Income poverty & 0.9 & $0.5-1.6$ & 2.1 & $1.6-2.9 * * *$ \\
\hline Exposure to two or more negative life events & 1.6 & $0.9-2.9$ & 2.9 & $2.2-3.9 * * *$ \\
\hline Poor family functioning ${ }^{2}$ & 1.4 & $0.8-2.5$ & 2.7 & $2.0-3.6^{* * *}$ \\
\hline Primary carer has no educational qualifications & 1.6 & $0.9-2.8$ & 1.9 & $1.4-2.6^{* * *}$ \\
\hline Household with no paid employment & 1.1 & $0.6-2.0$ & 2.7 & $2.0-3.7^{* * *}$ \\
\hline Mother with potential mental health disorder ${ }^{3}$ & 1.2 & $0.7-2.2$ & 2.7 & $2.0-3.6^{* * *}$ \\
\hline Maternal self-rated physical health less than 'good' & 1.4 & $0.7-2.6$ & 3.2 & $2.2-4.8^{* * *}$ \\
\hline
\end{tabular}

I. Those with missing data were excluded from analyses.

2. Family scores above cut-off $(>2)$ on the General Functioning Scale of the MacMaster Family Assessment Device.

3. Mother scores above cut-off $(>2)$ on the 12-item General Health Questionnaire (GHQ-12).

$* P<0.05 ; * * P<0.01$; ***P $<0.001$.

Nevertheless, accuracy in the identification of children would have been significantly strengthened if information had been available with regard to general intellectual functioning and adaptive behaviour. Unfortunately, although British Picture Vocabulary Scale scores were obtained (although not released through the UK Data Archive) for the 1999 cohort, these data were not collected in 2004.

The use of a measure of psychiatric disorder that has not been validated for use with children with intellectual disabilities does represent a threat to the internal validity of the results. There are two main grounds for concern regarding the generalisation of test validity to populations with intellectual disabilities. First, it has been argued that psychiatric disorders may manifest themselves differently among people with intellectual disabilities, and in particular people with more severe intellectual disabilities (Dykens, 2000; Wallander et al, 2003). For example, recent research has reported overall prevalence rates for psychiatric disorders in an adult population with primarily severe intellectual disabilities of $17 \%$ when using ICD-10 criteria and $35 \%$ when using criteria specifically developed for use with people with intellectual disabilities (Cooper et al, 2007). Notably, however, this discrepancy was primarily attributable to differences in rates of 'problem behaviours' identified by the two approaches $(0.1$ and $19 \%$ respectively). Given that the most commonly 

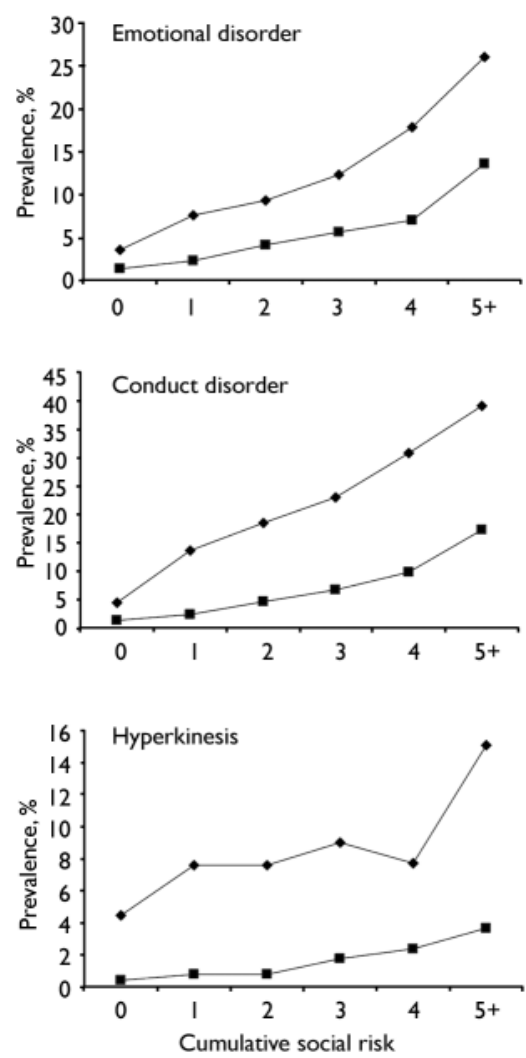

Fig. I Association between cumulative social risk and prevalence of emotional disorder, conduct disorder and hyperkinesis among children with $(\longrightarrow)$ and without $(\longrightarrow)$ intellectual disabilities.

diagnosed disorder in the present study was conduct disorder (a group of diagnoses that are likely to capture 'problem behaviours'), such discrepancies may be less likely in studies applying ICD-10 criteria to children. Unfortunately, no data are available at present on the actual correspondence of diagnoses of conduct disorders and the classification of problem or challenging behaviour in children with intellectual disabilities. Second, the identification of psychiatric disorders whose diagnostic criteria require self-report (e.g. obsessivecompulsive disorders) will obviously be problematic among groups who have difficulty in either accessing or reporting on internal states. The consequences of both of these issues for the present study would be to lead to an underestimation of prevalence rates for psychiatric disorders among the subsample of children with intellectual disabilities.

Finally, it must be kept in mind that the results of cross-sectional studies cannot

Table 3 Exposure of children with and without intellectual disabilities to social and environmental risk factors

\begin{tabular}{|c|c|c|c|}
\hline & \multicolumn{2}{|c|}{$\%$} & \multirow[t]{2}{*}{ OR $(95 \% \mathrm{Cl})$} \\
\hline & $\begin{array}{c}\text { With } \\
\text { intellectual } \\
\text { disability }\end{array}$ & $\begin{array}{l}\text { Without } \\
\text { intellectual } \\
\text { disability }\end{array}$ & \\
\hline Lone parent family & 30 & 23 & $\mathrm{I} .4(\mathrm{I} .2-\mathrm{I} .7)^{* * *}$ \\
\hline Income poverty & 47 & 30 & $2.1(1.8-2.5)^{* * *}$ \\
\hline Exposure to two or more negative life events & 37 & 24 & $1.9(1.6-2.2)^{* * *}$ \\
\hline Poor family functioning ${ }^{2}$ & 27 & 18 & $1.7(1.4-2.0)^{* * *}$ \\
\hline Primary carer has no educational qualifications & 38 & 20 & $2.5(2.1-3.0)^{* * *}$ \\
\hline Household with no paid employment & 30 & 14 & $2.6(2.2-3.1)^{* * *}$ \\
\hline Mother with potential mental health disorder ${ }^{3}$ & 33 & 24 & $1.6(1.3-1.9)^{* * *}$ \\
\hline Maternal self-rated physical health less than 'good' & 20 & 6 & $3.8(3.1-4.7)^{* * *}$ \\
\hline Exposure to three or more potential risk factors & 46 & 24 & $2.6(2.2-3.1)^{* * *}$ \\
\hline
\end{tabular}

I. Those with missing data were excluded from analyses.

2. Family scores above cut-off on the General Functioning Scale of the MacMaster Family Assessment Device.

3. Mother scores above cut-off on the 12-item General Health Questionnaire (GHQ-12).

$* P<0.05 ; * * P<0.01 ; * * *<<0.001$.

provide evidence of causality. This is particularly relevant to the analyses undertaken of the association between social/environmental factors and the prevalence of psychiatric disorders. These associations might reflect the causal influence of social adversity on psychopathology and, as such, would be consistent with the rapidly growing literature on the social determinants of physical and mental health (Marmot \& Wilkinson, 2006). They might also reflect the causal influence of child mental health on social adversity (Baker et al, 2003), the influence of unmeasured third variables (e.g. genetic factors) on risk of exposure to both social adversity and risk of child psychopathology or possible confounding arising from the operational definition of intellectual disabilities (e.g. low academic attainment or developmental progression being more likely among children with psychiatric disorders)

\section{Implications}

The high prevalence rates of psychopathology observed in the present study among children with intellectual disabilities are highly consistent with the results of previous research (Rutter et al, 1976; Einfeld \& Tonge, 1996; Linna et al, 1999; Dykens, 2000; Stromme \& Diseth, 2000; Dekker et al, 2002; Dekker \& Koot, 2003; Emerson, 2003; Wallander et al, 2003). These results must be of concern given the evidence that mental health problems have a major negative impact on the well-being, social inclusion and life opportunities of children (Quilgars et al, 2005). With regard to children with intellectual disabilities, for example, evidence suggests that mental health problems have a negative impact on the well-being of their families, and especially their mothers (Baker et al, 2003; Hatton \& Emerson, 2003), and are likely to lead to out-of-home placements, including the use of high-cost residential educational placements (Llewellyn et al, 2005).

Three main factors have been proposed to account for the high rates of psychopathology observed among children with intellectual disabilities (Dykens, 2000; Einfeld \& Emerson, 2007). First, studies undertaken on children in general have provided evidence of an association between lower IQ and psychiatric disorder (Goodman, 1995), an association possibly mediated by the role of IQ in determining a child's vulnerability or resilience when faced with adversity (Luthar, 2003). As a result, higher rates of psychopathology would be expected among children with intellectual disabilities given that intellectual impairment is a definitional characteristic of the group. Second, studies undertaken on children in general have also provided evidence of an association between exposure to social disadvantage and increased risk for psychopathology (Green et al, 
Table 4 Association between intellectual disability and psychiatric disorder before and after controlling for between-group differences in exposure to potential social/environmental risks ( $n=15900)^{\prime}$

\begin{tabular}{|c|c|c|c|}
\hline Variable & OR & $95 \% \mathrm{Cl}$ & $P$ \\
\hline \multicolumn{4}{|l|}{ Any emotional disorder: Block $I^{2}$} \\
\hline Intellectual disability & 3.59 & $(2.68-4.80)$ & $<0.001$ \\
\hline Male gender & 0.78 & $(0.67-0.92)$ & 0.003 \\
\hline Age & 0.91 & $(0.89-0.93)$ & $<0.001$ \\
\hline \multicolumn{4}{|l|}{ Any emotional disorder: Block $2^{3}$} \\
\hline Intellectual disability & 2.28 & $(1.67-3.12)$ & $<0.001$ \\
\hline Male gender & 0.77 & $(0.65-0.92)$ & 0.003 \\
\hline Age & 0.93 & $(0.90-0.95)$ & $<0.001$ \\
\hline Poor maternal physical health & 3.15 & $(2.54-3.90)$ & $<0.001$ \\
\hline Poor maternal mental health & 2.43 & $(2.04-2.89)$ & $<0.001$ \\
\hline Exposure to two or more adverse life events & 2.12 & $(1.78-2.52)$ & $<0.001$ \\
\hline Poor family functioning & 1.47 & $(1.22-1.77)$ & $<0.001$ \\
\hline Mother has no educational qualifications & 1.42 & $(1.17-1.72)$ & $<0.001$ \\
\hline Household with no paid employment & 1.40 & $(\mathrm{I} .14-\mathrm{I} .72)$ & 0.002 \\
\hline \multicolumn{4}{|l|}{ Any conduct disorder: Block I ${ }^{4}$} \\
\hline Intellectual disability & 5.68 & $(4.5 \mathrm{I}-7.15)$ & $<0.001$ \\
\hline Male gender & 2.05 & $(1.75-2.40)$ & $<0.001$ \\
\hline Age & 0.93 & $(0.91-0.95)$ & $<0.001$ \\
\hline \multicolumn{4}{|l|}{ Any conduct disorder: Block $2^{5}$} \\
\hline Intellectual disability & 3.88 & $(3.03-5.00)$ & $<0.001$ \\
\hline Male gender & 2.14 & $(1.82-2.52)$ & $<0.001$ \\
\hline Age & 0.95 & $(0.93-0.98)$ & $<0.001$ \\
\hline Poor family functioning & 2.25 & $(1.92-2.65)$ & $<0.001$ \\
\hline Poor maternal mental health & 2.07 & $(1.76-2.43)$ & $<0.001$ \\
\hline Exposure to two or more adverse life events & 2.04 & $(1.74-2.40)$ & $<0.001$ \\
\hline Poor maternal physical health & 1.83 & $(1.47-2.29)$ & $<0.001$ \\
\hline Poverty & 1.49 & $(1.24-1.80)$ & $<0.001$ \\
\hline Mother has no educational qualifications & 1.49 & $(1.25-1.78)$ & $<0.001$ \\
\hline Household without paid employment & 1.44 & $(1.17-1.77)$ & $<0.001$ \\
\hline \multicolumn{4}{|l|}{ Hyperkinesis: Block $1^{6}$} \\
\hline Intellectual disability & 8.20 & $(5.90-11.46)$ & $<0.001$ \\
\hline Male gender & 5.73 & $(3.89-8.44)$ & $<0.001$ \\
\hline Age & 1.00 & $(0.96-1.04)$ & NS \\
\hline \multicolumn{4}{|l|}{ Hyperkinesis: Block $2^{7}$} \\
\hline Intellectual disability & 5.79 & $(4.08-8.21)$ & $<0.001$ \\
\hline Male gender & 5.77 & $(3.8 \mathrm{I}-8.52)$ & $<0.001$ \\
\hline Age & 1.02 & $(0.97-1.06)$ & NS \\
\hline Exposure to two or more adverse life events & 2.02 & $(1.51-2.69)$ & $<0.001$ \\
\hline Poor maternal physical health & 1.81 & $(1.23-2.66)$ & 0.002 \\
\hline Poor family functioning & 1.62 & $(1.19-2.20)$ & 0.002 \\
\hline Poor maternal mental health & 1.58 & $(1.18-2.13)$ & 0.002 \\
\hline Household without paid employment & 1.43 & $(1.02-2.00)$ & 0.038 \\
\hline Mother has no educational qualifications & 1.39 & $(1.01-1.90)$ & 0.043 \\
\hline
\end{tabular}

NS, not significant.

I. Those with missing data were excluded from analyses.

2. $\chi^{2}=116.6$, d.f. $=3, P<0.001, r^{2}=0.026$.

3. $\chi^{2}=620.9$, d.f. $=9, P<0.001, r^{2}=0.137$.

4. $\chi^{2}=295.7$, d.f. $=3, P<0.001, r^{2}=0.058$.

5. $\chi^{2}=928.2$, d. $f=10, P<0.001, r^{2}=0.178$

6. $\chi^{2}=232.8$, d.f $=3, P<0.001, r^{2}=0.108$.

7. $\chi^{2}=330.8$, d.f. $=9, P<0.001, r^{2}=0.153$.
2005; BMA Board of Science, 2006). Increased rates of psychiatric disorders among children with intellectual disabilities would be predicted, therefore, given that such children are at significantly greater risk of exposure to social disadvantage (Emerson et al, 2006; Emerson \& Hatton, 2007). Third, the biological bases or sequelae of some syndromes associated with intellectual disability appear to be associated with increased susceptibility to some particular forms of psychopathology (Dykens, 2000; Dykens \& Hodapp, 2001; Hodapp \& Dykens, 2004; Einfeld \& Emerson, 2007).

The results of the present study are consistent with the notion that a potentially socially important proportion of the elevated risk for psychopathology among children and adolescents with intellectual disabilities may be a result of their increased rate of exposure to adverse social conditions (e.g. poverty, less than optimal parenting). Such an interpretation would suggest that approaches to reducing the personal, social and economic costs associated with psychiatric disorders among children with intellectual disabilities should focus on: (a) reducing their exposure to adverse social conditions (BMA Board of Science, 2006); (b) building the resilience of children with intellectual disabilities (and their families) when prevention of exposure to adversity cannot be guaranteed (Emerson, 2004).

\section{Future research}

It is now reasonably well established that intellectual disability is associated with an increased risk for psychopathology (Dykens, 2000; Wallander et al, 2003; Einfeld \& Emerson, 2007). Future research needs to identify the relative contribution of (and interplay between) intellectual impairment, social/environmental factors, psychological factors and biological factors to these elevated rates of psychiatric disorders. Addressing this demanding research agenda will require the use of more sophisticated longitudinal and experimental research designs, the validation of existing measures or the development of new measures of psychopathology applicable to children with intellectual disabilities, and the development and use of robust measures of social/environmental risk (Emerson et al, 2006). Exploring the interplay between biological and social factors will also require an increased emphasis on transdisciplinary research that bridges the gap between social epidemiology and behavioural genetics. 


\section{ACKNOWLEDGEMENTS}

The analyses were funded by the Foundation for People with Learning Disabilities.

\section{REFERENCES}

American Psychiatric Association (1994) Diagnostic and Statistical Manual of Mental Disorders (4th edn) (DSM-IV). APA

Baker, B. L., McIntyre, L. L., Blacher, J., et al (2003) Pre-school children with and without developmental delay: behaviour problems and parenting stress over time. Journal of Intellectual Disability Research, 47. 217-230.

BMA Board of Science (2006) Child and Adolescent Mental Health: A Guide for Healthcare Professionals. British Medical Association.

Cooper, S.-A., Smiley, E., Morrison, J., et al (2007) Mental ill-health in adults with intellectual disabilities: prevalence and associated factors. British Journal of

Psychiatry, 190, 27-35.

Dekker, M. C. \& Koot, H. M. (2003) DSM-IV disorders in children with borderline to moderate intellectual disability. I. Prevalence and impact. Journal of the American Academy of Child and Adolescent Psychiatry 42, 915-922.

Dekker, M. C., Koot, H. M., van-der-Ende, J., et al (2002) Emotional and behavioral problems in childre and adolescents with and without intellectual disability. Journal of Child Psychology and Psychiatry and Allied Disciplines, 43, 1087-1098.

Department of Work and Pensions (2007) Households Below Average Income (HBAl) 1994/5-2005/6 (Revised). Department of Work and Pensions.

Dykens, E. M. (2000) Psychopathology in children with intellectual disability. Journal of Child Psychology and Psychiatry, 4I, 407-4I7.

Dykens, E. M. \& Hodapp, R. M. (200I) Research in mental retardation: toward an etiological approach Journal of Child Psychology and Psychiatry, 42, 49-7l.

Einfeld, S. \& Emerson, E. (2007) Intellectual disability In Rutter's Child and Adolescent Psychiatry (eds M. Rutter, D. Bishop, D. Pine, et al, in press). Blackwell.

Einfeld, S. \& Tonge, B. J. (1996) Population prevalence of psychopathology in children and adolescents with intellectual disability. I. Epidemiological findings. Journal of Intellectual Disability Research, 40, 99-109.

Emerson, E. (2003) Prevalence of psychiatric disorders in children and adolescents with and without intellectua disability. Journal of Intellectual Disability Research, 47, $51-58$

ERIC EMERSON, PhD, CHRIS HATTON, PhD, Institute for Health Research, Lancaster University, Lancaster

Correspondence: Professor Eric Emerson, Institute for Health Research, Lancaster University, Lancaster, UK. Email: eric.emerson@lancaster.ac.uk

(First received 4 April 2007, final revision 17 July 2007, accepted 26 July 2007)

Emerson, E. (2004) Poverty and children with intellectual disabilities in the world's richer countries. Journal of Intellectual and Developmental Disability, 29, 319-337.

Emerson, E. \& Hatton, C. (2007) Contribution of socioeconomic position to health inequalities of British children and adolescents with intellectual disabilities. American Journal on Mental Retardation, II2, 140-150.

Emerson, E., Graham, H. \& Hatton, C. (2006) The measurement of poverty and socio-economic position in research involving people with intellectual disability. In International Review of Research in Mental Retardation (ed. M. Glidden), pp. 77-108. Academic Press.

Goldberg, D. \& Williams, P. (1988) A Users Guide to the General Health Questionnaire. nferNelson.

Goodman, R. (1995) The relationship between normal variation in $\mathrm{IQ}$ and common childhood psychopathology: a clinical study. European Child and Adolescent Psychiatry, 4, 187-196.

Goodman, R. (1999) The extended version of the Strengths and Difficulties Questionnaire as a guide to child psychiatric caseness and consequent burden. Journal of Child Psychology and Psychiatry, 40, 791-80I.

Goodman, R., Ford, T. \& Richards, H. (2000) The Development and Well-Being Assessment: description and initial validation of an integrated assessment of child and adolescent psychopathology. Journal of Child Psychology and Psychiatry, 4I, 645-656.

Green, H., McGinnity, A., Meltzer, H., et al (2005) Mental Health of Children and Young People in Britain, 2004. Palgrave MacMillan.

Hatton, C. \& Emerson, E. (2003) Families with a person with intellectual disabilities: stress and impact. Current Opinion in Psychiatry, I6, 497-501.

\section{Hodapp, R. M. \& Dykens, E. M. (2004) Studying} behavioural phenotypes: issues, benefits, challenges. In International Handbook of Applied Research in Intellectual Disabilities (eds E. Emerson, C. Hatton, T. Thompson, et al), pp. 203-220.Wiley.

Leonard, H. \& Wen, X. (2002) The epidemiology of mental retardation: challenges and opportunities in the new millennium. Mental Retardation and Developmental Disabilities Research Reviews, 8, I17-134.
Linna, S.-L., Piha, J., Kumpulainen, K., et al (1999) Psychiatric symptoms in children with intellectual disability. European Child and Adolescent Psychiatry, 8 77-82.

Llewellyn, G., McConnell, D., Thompson, K., et a (2005) Out-of-home placement of school age children with disabilities. Journal of Applied Research in Intellectual Disability, 18, 1-16.

Luthar, S. S. (ed.) (2003) Resilience and Vulnerability: Adaptation in the Context of Childhood Adversities. Cambridge University Press.

Marmot, M. \& Wilkinson, R. G. (eds) (2006) Social Determinants of Health (2nd edn). Oxford University Press.

Meltzer, H., Gatward, R., Goodman, R., et al (2000) Mental Health of Children and Adolescents in Great Britain. TSO (The Stationery Office)

Miller, I. W., Epstein, N. B., Bishop, D. S., et al (1985) The MacMaster Family Assessment Device: reliability and validity. Journal of Marital and Family Therapy, II 345-356.

Quilgars, D., Searle, B. \& Keung, A. (2005) Mental health and well-being. In The Well-Being of Children in the UK (eds J. Bradshaw \& E. Mayhew), pp. 134-160. Save the Children.

Rutter, M., Tizard, J., Yule, W., et al (1976) Isle of Wight studies 1964-1974. Psychological Medicine, 6, 313-332.

Stromme, P. \& Diseth, T. H. (2000) Prevalence of psychiatric diagnoses in children with mental retardation: data from a population-based study. Developmental Medicine and Child Neurology, 42, 266-270.

Wallander, J. L., Dekker, M. C. \& Koot, H. M. (2003) Psychopathology in children and adolescents with intellectual disability: measurement, prevalence, course, and risk. In International Review of Research in Mental Retardation (ed. L. Glidden), pp. 93-134. Elsevier.

World Health Organization (1993) The ICD-10 Classification of Mental and Behavioural Disorders: Diagnostic Criteria for Research.WHO. 